\title{
BMJ Open Fall-related attendance and associated hospitalisation of children and adolescents in Hong Kong: a 12-year retrospective study
}

\author{
James Chun-Yin Lee, Keith Tsz-Suen Tung, Tim M H Li, Frederick Ka-Wing Ho, \\ Patrick Ip, Wilfred Hing-Sang Wong, Chun-Bong Chow
}

To cite: Lee JC-Y, Tung KT$\mathrm{S}$, Li TMH, et al. Fall-related attendance and associated hospitalisation of children and adolescents in Hong Kong: a 12-year retrospective study. BMJ Open 2017;7: e013724. doi:10.1136/ bmjopen-2016-013724

- Prepublication history and additional material is available. To view please visit the journal (http://dx.doi.org/ 10.1136/bmjopen-2016013724)

Received 2 August 2016 Revised 3 October 2016 Accepted 5 October 2016

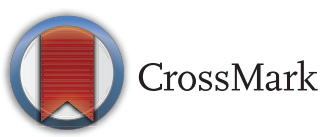

Department of Paediatrics and Adolescent Medicine, Li Ka Shing Faculty of Medicine, The University of Hong Kong, Hong Kong, China

Correspondence to Dr Chun-Bong Chow; chowcb@hku.hk

\section{ABSTRACT}

Objectives: The present study aimed to examine the trends and characteristics of fall-related attendance in accident and emergency department (AED) by injury type and the trend in associated average length of stay (LOS) among children and adolescents in Hong Kong.

Design: A retrospective approach was adopted. Setting: AED, involving all local public emergency departments from 2001 to 2012.

Participants: 63557 subjects aged $0-19$ years with fall injury record were included in the analysis.

Primary outcome measures: Fall-related injury number and rates were calculated and reported. Poisson and negative binomial regression models were used to study the trends of injury incidence rate at different body regions.

Results: AED fall-related attendance rate increased significantly with an annual percentage change of 4.45 $(95 \% \mathrm{Cl} 3.43$ to $5.47 \%, p<0.0001)$. The attendance number of male subjects was persistently higher than female subjects. The standardised rate of fracture injury increased by $1.31 \%(95 \% \mathrm{Cl} 0.56$ to $2.05 \%$, $\mathrm{p}<0.0001$ ) and that of non-fracture injury increased by $9.23 \%(95 \% \mathrm{Cl} 7.07$ to $11.43 \%, \mathrm{p}<0.0001)$ annually. Upper limb was the most frequently fractured location. It included forearm/elbow, shoulder/upper arm and wrist/hand with descending order of frequency. On the contrary, head was the most frequent non-fracture location, followed by forearm/elbow.

Conclusions: The rates of fall-related attendance have been increasing and still remain high. There were significant increases in non-fracture injuries. Fractures were most frequently found in the upper extremity of a child while the most common non-fracture location was head. It appears that more efforts should be made and preventive measures should be implemented for children and adolescents in Hong Kong.

\section{INTRODUCTION}

Falls are the leading cause of non-fatal injury in children and adolescents that impose significant burdens to the individuals and

\section{Strengths and limitations of this study}

- To authors' knowledge, this is the very first study on paediatric fall patterns using fracture and non-fracture categorisation.

- This study captures the changes of the injury pattern of falls with respect to time and serves as an indicator for the establishment of fall prevention programmes in children and adolescents.

- This study captures all accident and emergency department (AED) attendances in all public hospitals due to fall injuries in Hong Kong, which covers $>85 \%$ of the related AED attendances.

- The study may underestimate the incidence of fall injury in the population as only the AED figures were available.

- As the detailed mechanisms of fall remain unknown, further research such as case studies should be conducted in order to elucidate the mechanisms.

society. ${ }^{1-4}$ Previous studies have established an injury profile of Hong Kong, stating that over $40 \%$ of the child injuries were due to falls. ${ }^{5}{ }^{6}$ Fall-related injuries in childhood and adolescence may induce severe complications, such as traumatic brain injuries, ${ }^{7}$ serious head injuries ${ }^{8}$ and permanent disability, ${ }^{9}$ that adversely affect the future development and productivity of the children and adolescents. These would impose considerable burden to the healthcare system. ${ }^{10}$ The substantial impact of children and adolescent falls to the society can be reflected by the disability-adjusted life years (DALYs) lost. Globally, falls have been reported as the 13th most common cause of DALYs lost, of which children and adolescents accounted for over $50 \%$ of the fall-related DALYs lost. ${ }^{11}$

Given the high prevalence and substantial adverse effects of falls among children and adolescents, more efforts should focus on 
the preventive measures. However, different types and severity of fall-related injuries make the allocations of corresponding resources of fall-related injuries difficult. Hence, it is necessary to explore the mechanisms and potential factors that contribute to fall-related injury risks during childhood in order to inform the prevention programme design and implementation.

Falls have been identified as the most common cause of attendances to the accident and emergency department (AED) among all childhood injuries. ${ }^{12}$ Data on AED attendances and hospitalisation serve as key indicators to reflect on the severity and pattern of fall-related injuries. As hospital care represents the most expensive component of a healthcare system, ${ }^{13}$ making use of these information can help to identify the actual burden for different types of fall-related injuries caused in terms of the frequency of AED visit and the length of stay (LOS) in hospital admission. Moreover, data sources such as death registry can provide insightful information on the pattern of mortality causes. Hospitalisation data, together with the detailed code of diagnosis, have also been recognised as important information for assessing fall-related injuries. ${ }^{14}{ }^{15}$ Previous studies have demonstrated the usefulness of AED attendances and hospitalisation data in quantifying the burden of fall-related injuries. ${ }^{13}{ }^{16-18}$ However, many of these studies mainly focused on fall injuries among older adults or specific occupational groups. There were only few studies examining the fall-related injuries among adolescents and children, as well as the burden caused by different types of fall-related injuries to the healthcare system. This study therefore aimed to examine the trends and characteristics of fall-related AED attendance by injury type and the associated hospitalisation among children and adolescents in Hong Kong.

\section{METHODS}

This is a retrospective study which focuses on fall injury-related AED attendances among children and adolescents aged 0-19. All injury-related AED attendance data of children and adolescents covering the period from 1 January 2001 to 31 December 2012 were retrieved from the database of Hospital Authority (HA). HA is the official governing body of all public hospitals in Hong Kong, which covers the majority of 24-hour AED service in the territory. The HA database adopts the International Classification of Diseases, 9th revision (ICD-9) system for diagnosis, ${ }^{19}$ which reflects the types of the injuries of the patients. E-codes were required to identify any external causes of attendance admissions.

Records that met the following criteria were included in this study: (1) aged 0-19, (2) had a diagnosis of fallrelated injury (ICD-9 fall-related external cause code E880-E888) and (3) with a principal diagnostic code, except complications of medical care (ICD-9 codes
996-999). If the AED patient was subsequently hospitalised due to the same episode of injury, their corresponding inpatient records were also retrieved and matched. Inpatient diagnosis, if available, was used preferentially over AED diagnosis.

The trauma types were stratified into fracture (ICD-9 codes 800-829) and non-fracture injury (ICD-9 codes beyond 829, excluding 996-999). In general, X-ray is used for all fracture diagnosis in the AED treatment in Hong Kong. The confirmed fracture locations of the patients were then recorded in terms of ICD-9 codes into the HA database. To understand the mechanisms of the injury types, fracture and non-fracture injuries were further divided into subcategories representing different body regions. For instance, based on ICD-9 codes, the fall-related fractures have been grouped into the fracture of hip (820), fracture of femur (821), upper extremity fractures (fractures of shoulder/upper arm (810-812), forearm/elbow (813), wrist/hand (814-817)), lower extremity fractures (fracture of lower leg/knee (822823), ankle/foot (824-826)) and central fractures (fractures of skull/face (800-804), neck/trunk (805-809)). Similar but a more complicated coding (see online supplementary appendix I) in non-fracture group also allowed us to break it down into hip/thigh, upper extremity (shoulder/upper arm, forearm/elbow and wrist/hand), lower extremity (lower leg/knee and ankle/foot), head, neck/trunk, abdomen/lower back and others.

In addition to the detailed descriptions of the injury episode, the HA databases also provide basic demographic information including age, gender, as well as the LOS during the subsequent hospitalisation. This information can act as a proxy for the injury severity. Stratified by the nature of the injury, the average LOS of an individual from fracture group can be compared with that from non-fracture group. Midyear sex-specific population data of each of the 12 years were obtained through Demographic Statistics Section of Census and Statistics Department, Hong Kong Special Administrative Region, to compute the attendance rate of fall-related injury.

\section{Statistical analysis}

Based on the number of occurrence with respect to different body regions across years, fall injury-related attendance rates could be calculated by dividing the number of episodes by the corresponding population size. The rates were represented in number per 100000 persons for clarity.

To examine the trend of fall-related attendance, Poisson regression model was used primarily to determine the statistical significance of changes in the number of injury across the 2 years. However, the negative binomial regression model was used in the analysis if there was overdispersion. Regardless of the distribution used, natural logarithm of midyear population sizes, $\log (\mathrm{N})$, of $0-19$ for each year from 2001 to 2012 were 
used as an offset in the regression equation to adjust for the effect on varying population figures, with the following model specification:

$$
\log \left(E\left[Y_{t}\right]\right)=\alpha+\beta\left(t_{\text {trend }}\right)+\log (\mathrm{N})+\varepsilon .
$$

In the model, $\mathrm{E}\left[\mathrm{Y}_{\mathrm{t}}\right]$ is the expected number of fallrelated attendance in Hong Kong in year t. Generally, the exponential of the regression coefficient $(\beta)$ in the regression model refers to incidence risk ratio, which captures the multiplicative effect of independent variable on the response variable. Statistical significance of $\beta$ would indicate that there is a multiplicative effect on the year trend towards the adjusted risk in fall-related attendance number. All results were presented as an annual percentage change $\left(e^{\beta}-1\right)$ in the fall-related attendance rates under the regression model. The 95\% CIs were provided, assuming $\beta$ follows a normal distribution.

Average LOS was derived as a general indicator for severity of the fall-related injury by summing up all the LOS and divided it by the number of admissions to the inpatient care unit in the group. The LOS in inpatient care unit was $\geq 1$ if the patient was hospitalised after diagnosis in AED. Otherwise, it was expressed as zero meaning that the patient was discharged subsequently. An overall trend of the severity was observed. Subgroup analysis was also carried out for fracture group and nonfracture group for comparison on the severity of fall- related injury. Results of the analyses with $\mathrm{p}<0.05$ would be considered as statistically significant. All statistical computations were performed by using statistical software $\mathrm{R}$ ( $\mathrm{R}$ for Windows, V.3.2.4).

\section{RESULTS}

There were a total number of 63557 subjects aged 0-19 who attended AED due to fall-related injury from 2001 to 2012, of which 37498 patients were admitted to the inpatients. The number of fall-related attendance by nature and year is reported in table 1 . Throughout the 12-year period of time, the annual number of attendance increased by about 17\% from 4789 in 2001 to 5623 in 2012. Stratified by gender, the increase in the annual intake was $8.8 \%(3393-3691)$ in male subjects and $38 \%$ (1396-1932) in female subjects, respectively. The attendance number due to fracture dropped by $5.5 \%$ from 3135 to 2962 while that due to non-fracture injury increased by $61 \%$ from 1654 to 2661 . Moreover, the proportion of fracture cases in the annual admissions dropped from $65 \%$ initially to $53 \%$ at the end of the study period. The fracture locations were mainly 'forearm/elbow', 'shoulder/upper arm' and 'wrist/ hand', sharing $44 \%, 25 \%$ and $11 \%$ of the fracture cases, respectively, in 2001, and the pattern was consistent throughout the years. On the contrary, head was mainly

\begin{tabular}{|c|c|c|c|c|c|c|c|c|c|c|c|c|c|}
\hline Injury typelyear & 2001 & 2002 & 2003 & 2004 & 2005 & 2006 & 2007 & 2008 & 2009 & 2010 & 2011 & 2012 & Total \\
\hline Total AED cases & 4789 & 4934 & 4156 & 5073 & 4960 & 5597 & 5706 & 5547 & 5341 & 5961 & 5870 & 5623 & 63557 \\
\hline Males & 3393 & 3411 & 2962 & 3598 & 3508 & 3862 & 3934 & 3809 & 3701 & 3984 & 3953 & 3691 & 43806 \\
\hline Females & 1396 & 1523 & 1194 & 1475 & 1452 & 1735 & 1772 & 1738 & 1640 & 1977 & 1917 & 1932 & 19751 \\
\hline \multicolumn{14}{|l|}{ Fracture location } \\
\hline All fracture injuries & 3135 & 3297 & 2943 & 3308 & 3184 & 3388 & 3191 & 2947 & 2902 & 2963 & 3025 & 2962 & 37245 \\
\hline Forearm/elbow & 1385 & 1477 & 1315 & 1603 & 1505 & 1626 & 1524 & 1399 & 1376 & 1430 & 1404 & 1281 & 17325 \\
\hline Shoulder/upper arm & 776 & 810 & 745 & 720 & 719 & 741 & 688 & 599 & 610 & 596 & 649 & 699 & 8352 \\
\hline Wrist/hand & 340 & 380 & 316 & 354 & 339 & 373 & 349 & 342 & 347 & 387 & 380 & 379 & 4286 \\
\hline Lower leg/knee & 251 & 229 & 240 & 251 & 246 & 244 & 235 & 229 & 214 & 187 & 194 & 229 & 2749 \\
\hline Ankle/foot & 228 & 237 & 193 & 247 & 262 & 265 & 265 & 252 & 238 & 237 & 273 & 268 & 2965 \\
\hline Skull/face & 107 & 103 & 81 & 86 & 71 & 88 & 66 & 80 & 72 & 80 & 76 & 74 & 984 \\
\hline Femur & 25 & 42 & 32 & 27 & 18 & 33 & 38 & 29 & 24 & 27 & 20 & 21 & 336 \\
\hline Neck/trunk & 14 & 13 & 14 & 15 & 13 & 14 & 17 & 14 & 16 & 9 & 22 & 8 & 169 \\
\hline Hip & 9 & 6 & 7 & 5 & 11 & 4 & 9 & 3 & 5 & 10 & 7 & 3 & 79 \\
\hline \multicolumn{14}{|l|}{ Non-fracture location } \\
\hline All non-fracture injuries & 1654 & 1637 & 1213 & 1765 & 1776 & 2209 & 2515 & 2600 & 2439 & 2998 & 2845 & 2661 & 26312 \\
\hline Head & 1296 & 1363 & 974 & 1505 & 1455 & 1621 & 1742 & 1846 & 1595 & 1921 & 1829 & 1725 & 18872 \\
\hline Lower leg/knee & 90 & 65 & 53 & 64 & 66 & 114 & 136 & 98 & 117 & 163 & 165 & 129 & 1260 \\
\hline Forearm/elbow & 90 & 72 & 65 & 50 & 58 & 84 & 129 & 117 & 120 & 191 & 133 & 123 & 1232 \\
\hline Ankle/foot & 48 & 27 & 26 & 35 & 43 & 111 & 132 & 169 & 169 & 225 & 198 & 193 & 1376 \\
\hline Others & 42 & 32 & 37 & 46 & 72 & 131 & 160 & 172 & 225 & 218 & 238 & 240 & 1613 \\
\hline Neck/trunk & 27 & 25 & 24 & 26 & 32 & 60 & 89 & 62 & 79 & 112 & 99 & 104 & 739 \\
\hline Wrist/hand & 26 & 18 & 12 & 20 & 23 & 44 & 81 & 84 & 76 & 97 & 113 & 90 & 684 \\
\hline Hip/thigh & 22 & 21 & 14 & 9 & 18 & 25 & 33 & 36 & 49 & 49 & 50 & 46 & 372 \\
\hline Abdomen/lower back & 8 & 9 & 4 & 7 & 5 & 10 & 10 & 12 & 5 & 14 & 13 & 7 & 104 \\
\hline Shoulder/upper arm & 5 & 5 & 4 & 3 & 4 & 9 & 3 & 4 & 4 & 8 & 7 & 4 & 60 \\
\hline
\end{tabular}

AED, accident and emergency department. 
the location where non-fracture injury occurred, owning $78 \%$ in 2001.

The overall population size-adjusted fall-related attendance rate was significantly increased by an average of $4.45 \% \quad(95 \%$ CI 3.43 to $5.47 \%, \mathrm{p}<0.0001)$ annually throughout a 12-year time period (table 2). Stratified by gender, the annual percentage change for male subjects was $1.6 \%$ (95\% CI 0.65 to $2.56 \%, \mathrm{p}<0.0001$ ) which was lower compared with female subjects at $3.56 \%(95 \%$ CI 2.28 to $4.85 \%, \mathrm{p}<0.0001)$. Stratified by nature of injury, the fracture group had a significant increase of $1.31 \%$ in rate $(95 \%$ CI 0.56 to $2.05 \%, \mathrm{p}<0.0001)$ while that of the non-fracture group was also significant with an annual percentage rate as high as $9.23 \%$ (95\% CI 7.07 to $11.43 \%, \mathrm{p}<0.0001)$. In the fracture group, only forearm/ elbow, wrist/hand and ankle/foot had significantly positive annual percentage change. Other subcategories of fracture group, including the majority of the less numerous locations, were insignificant. On the contrary, all non-fracture subgroups had significant positive growth rates except for shoulder/upper arm. Specifically, head had persistently the highest rate in the non-fracture group with $6.28 \%$ annual percentage rate of change (95\% CI 4.36 to $8.24 \%, \mathrm{p}<0.0001)$.

The admissions from AED to inpatient care unit dropped from 4301 persons in 2001 to 2668 persons in 2012 (table 3). Given that the total AED cases have increased, the number of patients being discharged after visiting AED due to fall injury should have a conflicting trend with the referral cases. The immediate discharge number had a sevenfold increase to 3281 in 2012 compared with the previous number at 488 . The relationship can be illustrated by the intersection of the two lines at around year 2008 in figure 1. Fracture group has shown a similar pattern in the decomposition with the overall trend (figure 2) in the sense that the referral was reducing and the immediate discharge cases were booming; however, there was no crossing of the curves. For the non-fracture group, the crossing appeared early in 2003, while the referral to inpatient has become stable beyond the intersection. The increase of the nonfracture AED cases was solely driven by the number of immediate discharge cases, as illustrated in figure 3.

The average LOS of the referred cases in each subgroup was rather stable throughout the 12 years, showed by the levelled lines in figure 4 . The average LOS among the fracture group was substantially higher than the non-fracture group. The minimum difference between the average LOS of fracture group and nonfracture group was 0.635 day/person and the maximum difference was 1 day/person.

\section{DISCUSSION}

The current study aimed to investigate the trend and characteristics of fall injury attendances in AED and the related LOS among the induced hospitalised patients from 2001 to 2012. Over the 12 years, the number of overall fall-related attendance in Hong Kong has been increased and still remains high. Particularly, there have been a growing number of non-fracture cases, whereas the fracture cases remain fairly stable. With the shrinking population size of the children and adolescents aged 0-19 over the years from 1559736 to 1230000 , the population size-standardised rates of the overall fallrelated attendance have increased substantially among fracture and non-fracture groups.

Two unusual troughs in the admission number were illustrated in figures 1-3 with one appearing during the 2003 severe acute respiratory syndrome (SARS) outbreak, while another during the $2009 \mathrm{H} 1 \mathrm{~N} 1$ outbreak. ${ }^{20}$ The drops were larger in the non-fracture group $(25.9 \%$ in 2003 and $6.2 \%$ in 2009) than fracture group (10.7\% in 2003 and $1.5 \%$ in 2009). Such decrements in AED admission have also been observed worldwide during these outbreaks. ${ }^{21}$ During the outbreak of highly infectious and fatal diseases, AED became a comparatively high-risk place due to the admissions of newly infected patients. We suspect that although more severe patients with fracture injury would still attend AED for medical care services given no other alternatives for treatments, less severe patients with non-fracture injury would avoid attending AED for treatment during the disease outbreak due to their fear of being infected. ${ }^{22}$

When we broke down the overall fall-related attendance into inpatient admissions and discharge cases (table 3), it was observed that the number of admissions to inpatient care unit was dropping in both groups while the immediate discharge cases were on the rising trend across the years. The increase in the overall attendance number was driven by drastic increments in immediate discharged cases in fracture and non-fracture groups. The increase in the overall attendance was driven by drastic increments in immediate discharged cases in fracture and non-fracture groups, which could be related the health seeking behaviour of the children's carer. As shown in previous studies, accessibility, convenience, ${ }^{23}$ high availability ${ }^{24}$ and confidence in the emergency care are all potential factors that could have driven the increasing number in attendance. Moreover, guardians/carers might sometimes overestimate the severity of their children's injuries, ${ }^{25}$ causing unnecessary usage of the AED services. This may require a structural change in the resource usage of AED for falls since increasing effort was put for treatment of mild cases. Owing to the fact that overcrowding was a problem to emergency departments in Hong Kong, ${ }^{20}$ administrative measures such as providing more community care, primary care, community education and change in the admission criteria may relieve possible inappropriate usage of AED services. ${ }^{26}{ }^{27}$ Nonetheless, the boom in non-fracture attendance could be explained by the enhanced awareness of the parents on the safety of their children or improvements in the reputation of AED.

Previous research found that the most common type of fall which results in hospitalisation among 10-year 


\begin{tabular}{|c|c|c|c|c|c|c|c|c|c|c|c|c|c|}
\hline Injury type & 2001 & 2002 & 2003 & 2004 & 2005 & 2006 & 2007 & 2008 & 2009 & 2010 & 2011 & 2012 & Annual $\%$ change (95\% Cls) \\
\hline Total AED cases & 307 & 327.2 & 283.6 & 352.7 & 354.1 & 405.9 & 420.6 & 416 & 413.7 & 470 & 470.7 & 457.2 & $4.45^{\star \star}(3.43$ to 5.47$)$ \\
\hline Males & 421.1 & 439.4 & 393.5 & 487.7 & 489 & 545.5 & 563.6 & 553.9 & 555.7 & 608.6 & 614.4 & 582.1 & $1.60^{\star *}(0.65$ to 2.56$)$ \\
\hline Females & 185.1 & 208.2 & 167.5 & 210.6 & 212.5 & 258.6 & 269.1 & 269.2 & 262.4 & 322.2 & 317.6 & 324.2 & $3.56^{\star \star}(2.28$ to 4.85$)$ \\
\hline \multicolumn{14}{|l|}{ Fracture location } \\
\hline All fracture injuries & 251.4 & 260 & 227.9 & 248.1 & 234.7 & 245.7 & 227.8 & 204.9 & 198 & 196.5 & 193.9 & 240.8 & $1.31^{\star \star}(0.56$ to 2.05$)$ \\
\hline Forearm/elbow & 91.8 & 94.7 & 106.9 & 128.5 & 118.7 & 125.9 & 114.3 & 103.1 & 99.8 & 102.1 & 97.6 & 87.4 & $1.48^{\star *}(0.33$ to 2.65$)$ \\
\hline Shoulder/upper arm & 54 & 55.3 & 49.4 & 46.2 & 58.5 & 59.4 & 54.3 & 46.4 & 45.7 & 43.9 & 47.1 & 49.9 & $-0.02(-1.01$ to 0.98$)$ \\
\hline Wrist/hand & 21.8 & 30.9 & 25.3 & 27.9 & 26.3 & 28 & 25.7 & 24.8 & 24.8 & 26.9 & 25.9 & 25.1 & $3.01^{* *}(2.12$ to 3.91$)$ \\
\hline Lower leg/knee & 17.1 & 15.2 & 15.4 & 20.4 & 19.7 & 19.2 & 18.2 & 17.2 & 15.8 & 13.6 & 13.9 & 15.9 & $0.33(-0.75$ to 1.42$)$ \\
\hline Ankle/foot & 16.3 & 16.5 & 13.2 & 16.4 & 16.8 & 21.5 & 21.2 & 19.9 & 18.4 & 17.8 & 20.1 & 19.4 & $3.58^{\star *}$ (2.51 to 4.66$)$ \\
\hline Skull/face & 7.8 & 7.4 & 5.6 & 5.9 & 4.7 & 5.6 & 5.4 & 6.4 & 5.7 & 6.2 & 5.7 & 5.5 & $-0.77(-2.55$ to 1.04$)$ \\
\hline Femur & 1.9 & 3.1 & 2.4 & 2 & 1.3 & 2.3 & 2.6 & 1.9 & 1.5 & 2.2 & 1.6 & 1.7 & $-1.05(-4.07$ to 2.07$)$ \\
\hline Neck/trunk & 1 & 0.9 & 1 & 1 & 1.1 & 1.1 & 1.3 & 1 & 1.1 & 0.6 & 1.8 & 0.6 & $1.91(-2.44$ to 6.45$)$ \\
\hline Hip & 0.7 & 0.4 & 0.5 & 0.3 & 0.8 & 0.3 & 0.6 & 0.2 & 0.4 & 0.8 & 0.5 & 0.2 & $-0.8(-6.95$ to 5.75$)$ \\
\hline \multicolumn{14}{|l|}{ Non-fracture location } \\
\hline All non-fracture injuries & 134.5 & 133.1 & 98.6 & 143.5 & 144.4 & 179.6 & 204.5 & 211.4 & 198.3 & 243.7 & 231.3 & 216.3 & $9.23^{\star \star}(7.07$ to 11.43$)$ \\
\hline Head & 83.1 & 87.4 & 62.4 & 96.5 & 93.3 & 103.9 & 111.7 & 118.4 & 102.3 & 123.2 & 117.3 & 110.6 & $6.28^{\star \star}(4.36$ to 8.24$)$ \\
\hline Lower leg/knee & 6.6 & 5.3 & 4.8 & 3.7 & 4.3 & 6.2 & 9.5 & 8.6 & 8.8 & 14.1 & 9.8 & 9.1 & $11.05^{\star \star}(7.17$ to 15.08$)$ \\
\hline Forearm/elbow & 6.5 & 4.7 & 3.8 & 4.6 & 4.8 & 8.3 & 9.9 & 7.1 & 8.5 & 11.8 & 12 & 9.4 & $10.71^{\star *}(6.26$ to 15.35$)$ \\
\hline Ankle/foot & 3.2 & 1.8 & 1.7 & 2.3 & 2.9 & 7.4 & 8.8 & 11.2 & 11.2 & 14.9 & 13.1 & 12.8 & $25.29^{\star \star}(18.69$ to 32.26$)$ \\
\hline Neck/trunk & 1.9 & 1.3 & 0.9 & 1.5 & 1.7 & 3.3 & 6.1 & 6.3 & 5.7 & 7.3 & 8.5 & 6.7 & $19.60^{\star *}(15.15$ to 24.21$)$ \\
\hline Wrist/hand & 1.8 & 1.7 & 1.6 & 1.8 & 2.2 & 4.1 & 6.1 & 4.2 & 5.4 & 7.6 & 6.8 & 7.1 & $23.37^{\star \star}(17.03$ to 30.06$)$ \\
\hline Hip/thigh & 1.6 & 1.5 & 1 & 0.6 & 1.3 & 1.8 & 2.4 & 2.6 & 3.5 & 3.5 & 3.6 & 3.3 & $15.15^{\star *}(11.65$ to 18.77$)$ \\
\hline Abdomen/lower back & 0.6 & 0.7 & 0.3 & 0.5 & 0.4 & 0.8 & 0.8 & 0.9 & 0.4 & 1.1 & 1 & 0.5 & $6.60^{\star}(0.80$ to 12.73$)$ \\
\hline Shoulder/upper arm & 0.4 & 0.4 & 0.3 & 0.2 & 0.3 & 0.7 & 0.2 & 0.3 & 0.3 & 0.6 & 0.6 & 0.3 & $4.58(-2.81$ to 12.54$)$ \\
\hline
\end{tabular}


Table 3 Referral from AED to inpatient care units of fall-related attendance of subjects aged 0-19 from 2001 to 2012

\begin{tabular}{lllllllllllll}
\hline Length of staylyear & $\mathbf{2 0 0 1}$ & $\mathbf{2 0 0 2}$ & $\mathbf{2 0 0 3}$ & $\mathbf{2 0 0 4}$ & $\mathbf{2 0 0 5}$ & $\mathbf{2 0 0 6}$ & $\mathbf{2 0 0 7}$ & $\mathbf{2 0 0 8}$ & $\mathbf{2 0 0 9}$ & $\mathbf{2 0 1 0}$ & $\mathbf{2 0 1 1}$ & $\mathbf{2 0 1 2}$ \\
\hline Total AED cases & 4789 & 4934 & 4156 & 5073 & 4960 & 5597 & 5706 & 5547 & 5341 & 5961 & 5870 & 5623 \\
$\quad$ Referral to inpatients & 4301 & 4125 & 3337 & 3389 & 3126 & 3184 & 2895 & 2733 & 2688 & 2463 & 2589 & 2668 \\
Immediate discharge & 488 & 809 & 819 & 1684 & 1834 & 2413 & 2811 & 2814 & 2653 & 3498 & 3281 & 2955 \\
$\quad$ Average LOS (days) & 2.14 & 2.31 & 2.17 & 2.23 & 2.21 & 2.14 & 2.22 & 2.26 & 2.12 & 2.14 & 2.14 & 2.04 \\
Fracture & & & & & & & & & & & & \\
$\quad$ All fracture injuries & 3135 & 3297 & 2943 & 3308 & 3184 & 3388 & 3191 & 2947 & 2902 & 2963 & 3025 & 2962 \\
$\quad$ Referral to inpatients & 2917 & 3025 & 2626 & 2668 & 2488 & 2479 & 2215 & 2055 & 2007 & 1798 & 1933 & 2028 \\
Immediate discharge & 218 & 272 & 317 & 640 & 696 & 909 & 976 & 892 & 895 & 1165 & 1092 & 934 \\
Average LOS (days) & 2.40 & 2.58 & 2.34 & 2.39 & 2.37 & 2.28 & 2.43 & 2.42 & 2.30 & 2.38 & 2.30 & 2.25 \\
Non-fracture & & & & & & & & & & & & \\
$\quad$ All non-fracture injuries & 1654 & 1637 & 1213 & 1765 & 1776 & 2209 & 2515 & 2600 & 2439 & 2998 & 2845 & 2661 \\
$\quad$ Referral to inpatients & 1384 & 1100 & 711 & 721 & 638 & 705 & 680 & 678 & 681 & 665 & 656 & 640 \\
Immediate discharge & 270 & 537 & 502 & 1044 & 1138 & 1504 & 1835 & 1922 & 1758 & 2333 & 2189 & 2021 \\
Average LOS (days) & 1.60 & 1.57 & 1.56 & 1.62 & 1.61 & 1.63 & 1.52 & 1.76 & 1.59 & 1.47 & 1.67 & 1.38 \\
\hline AED,accident and emergency department; LOS, length of stay. & & & & & & &
\end{tabular}

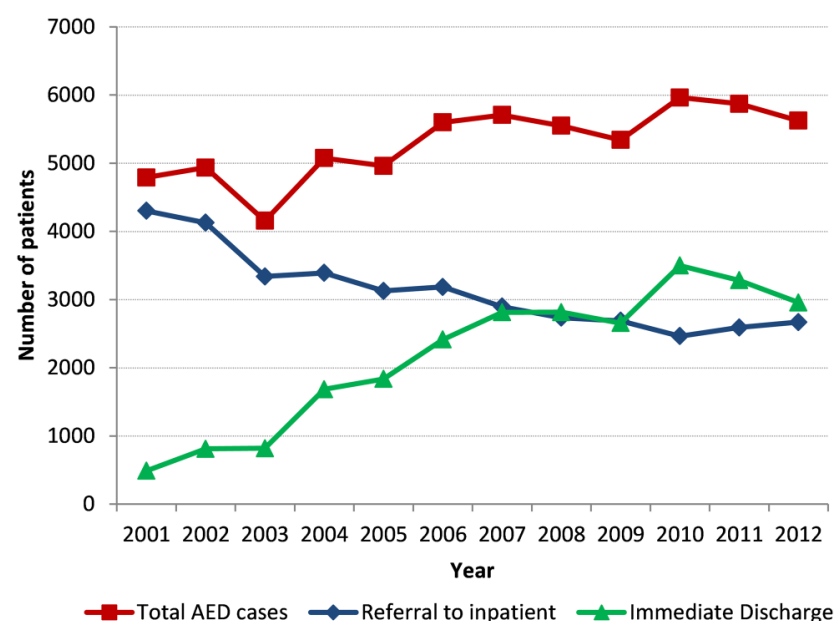

Figure 1 Breakdown of the overall AED fall-related cases into referral to inpatient care unit and immediate discharge. AED, accident and emergency department.

olds or younger was falling from one level to another, including falling from playground equipment, beds, tables and chairs. On the contrary, patients aged 1019 were frequently injured because of falling on the same level instead, either slipping or having collisions with others. ${ }^{13}$ In our study, while the rate of nonfracture injury admissions in all body regions increased significantly, ankle and foot injuries had the highest annual percentage change followed by wrist and hand injuries. Head injuries had the highest proportion accounting for the number of fall injury attendance in the non-fracture injuries. It escalated to about 1.6 times of its initial value over the 12-year study period. However, such escalation could be accounted by a pure increase in head incidence or an improvement in diagnostic process. Research showed that young children having minor head injuries had low risk to coincide with clinically significant traumatic brain injury. ${ }^{28}$

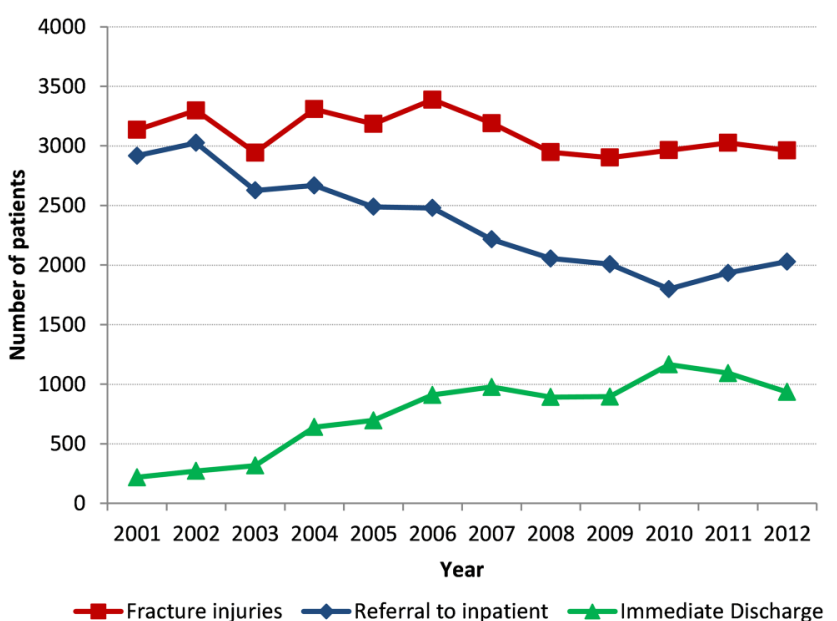

Figure 2 Breakdown of the AED fall-related fracture cases into referral to inpatient care unit and immediate discharge. AED, accident and emergency department.

Our results, as compared with a previous study, suggested that non-fractures appeared most frequently on head consistently among the young and the elderly (aged 65+). Yet, these two groups of people were different in the pattern of fracture-injured body region; the children and adolescents were most commonly injured with fractures on their upper extremity, while fractures on hips were the most common among the elderly. ${ }^{16}$ The explanation may lie on the differences in the falling mechanisms and the response time to accidents with respect to children and the elderly. Wrist fractures are usually associated with falling forward or backward with an outstretched hand while hip fractures are often due to falls to the side. ${ }^{29}$ It was suggested that wrist fractures are more common than hip fractures between ages 65 and 75. However, hip fractures become predominate in ages $75+$, probably because of slowed reflexes and loss of ability to protect their hips with their hands. ${ }^{30}$ When fall occurs, the younger individuals have more available 
Figure 3 Breakdown of the AED fall-related non-fracture cases into referral to inpatient care unit and immediate discharge. AED, accident and emergency department.

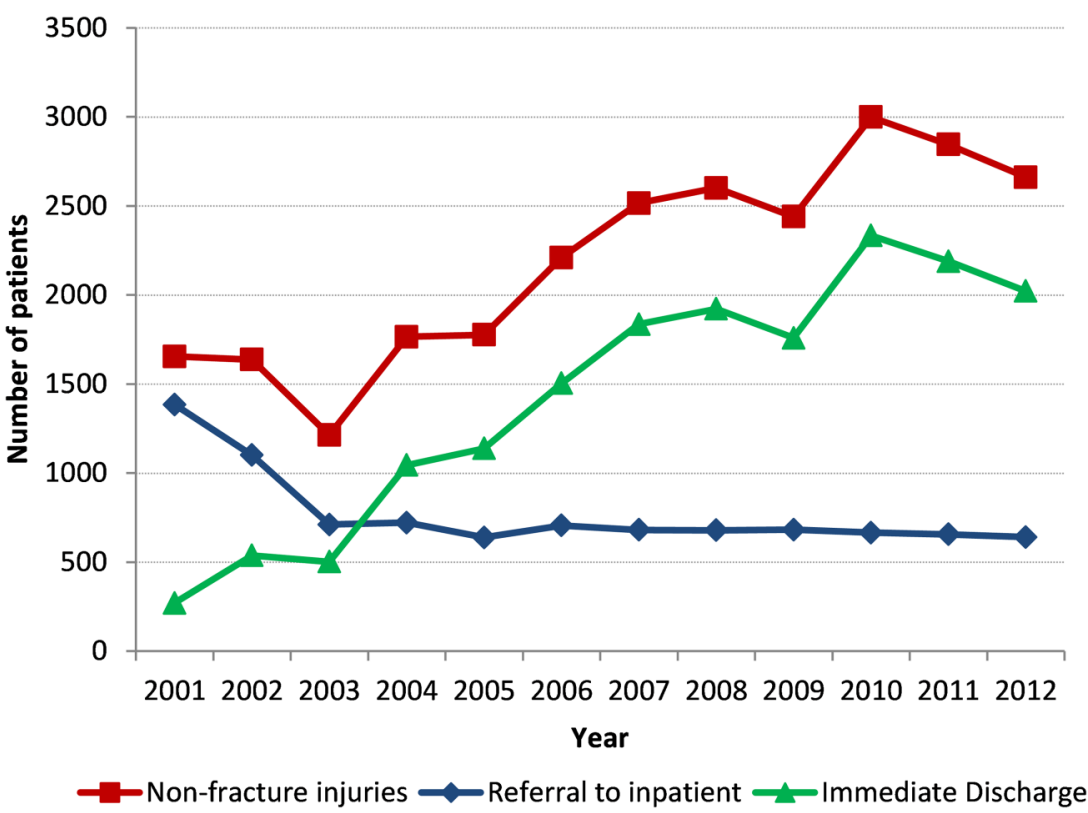

admissions and be excluded easily, potential double counting may compromise our study. Second, this study only included those subjects with a principal code and without complications of medical care. Hence, the number and the rates may not accurately reflect the actual admissions for each type of injury sustained. Third, we adopted LOS as a proxy for severity of injury which has been criticised for its instability in estimating the injury severity as compared with other standardised scores. However, LOS is a readily available statistic that can be easily understood by general public and LOS can reflect the potential improvements of medical treatments and policy changes in hospital for inpatients over time, which are of interest in our study. Finally, the current study did not examine the details of how falling mechanisms would result in injury of particular body regions among children and adolescents. Fall-preventive measures may be difficult to be implemented in practice. Further study would be needed to elucidate these mechanisms in the near future.

response time than the elderly, and hence they can sufficiently use their hand to land on the ground to protect their hips and prevent their heads from damages. ${ }^{31}{ }^{32}$ Therefore, it is most likely to see that the fracture appeared on the parts of the upper extremity of children and adolescents.

Figure 4 demonstrates the trend of the average LOS of hospitalised patients with fall-related attendance. It reflects that the injuries among fracture group are more severe than non-fracture group, and fracture cases impose a heavier burden on the healthcare system. Moreover, a stable trend in severity of injuries has been observed, as reflected by the average LOS. However, there might be other influential factors such as the administrative policies of hospitals that would certainly alter the LOS of patients.

There are some limitations in our study. First, as readmissions to AED were unlikely to be separated from new

\section{CONCLUSION}

The study shows a surprising phenomenon that although our child and adolescent population was shrinking, the relative number of overall fall-related attendance continued to increase. It is possible that guardians/carers of children became more aware of their children's injuries, and more willing to seek professional help. Appropriate administrative measures in AED can be proposed to relieve possible inappropriate use of services and reduce the waiting time. More importantly, the increased number of childhood injuries signals the inadequacy of preventive measures for fall-related injuries. Different parties should work together and implement more effective preventive measures. For instance, schools can install soft rubber and waterproof floor for students' playgrounds, while parents can create a safe 
home environment for their children. A further study on disseminating safety knowledge to parents will be conducted. ${ }^{33}$ In the future, governments should coordinate different parties with appropriate public policy to protect our children from fall-related injuries.

Contributors C-BC conceptualised and designed the study. JC-YL drafted the initial manuscript and performed major parts of the statistical analysis. KT-ST performed literature review and drafted the initial manuscript. TMHL interpreted the results of the data and critically revised the manuscript. FK-WH assisted in performing statistical analysis and revised the methodology of the study. PI critically revised the manuscript and drafted a part of the manuscript. WH-SW critically reviewed the manuscript. All authors have approved the final manuscript as submitted.

Competing interests None declared.

Ethics approval Institutional Review Board of the University of Hong Kong/ Hospital Authority Hong Kong West Cluster.

Provenance and peer review Not commissioned; externally peer reviewed.

Data sharing statement No additional data are available.

Open Access This is an Open Access article distributed in accordance with the Creative Commons Attribution Non Commercial (CC BY-NC 4.0) license, which permits others to distribute, remix, adapt, build upon this work noncommercially, and license their derivative works on different terms, provided the original work is properly cited and the use is non-commercial. See: http:// creativecommons.org/licenses/by-nc/4.0/

\section{REFERENCES}

1. Hu M, Hu GQ, Sun ZQ, et al. Epidemiological survey of the prevalence of non-fatal injury among children aged 5-14 years in China. Biomed Environ Sci 2012;25:407-12.

2. Halawa EF, Barakat A, Rizk HII, et al. Epidemiology of non-fatal injuries among Egyptian children: a community-based cross-sectional survey. BMC Public Health 2015;15:1248.

3. Ballesteros MF, Schieber RA, Gilchrist J, et al. Differential ranking of causes of fatal versus non-fatal injuries among US children. Inj Prev 2003;9:173-6.

4. Rivara FP. Fatal and non-fatal farm injuries to children and adolescents in the United States, 1990-3. Inj Prev 1997;3:190-4.

5. Chan CC, Cheng JC, Wong TW, et al. An international comparison of childhood injuries in Hong Kong. Inj Prev 2000;6:20-3.

6. Department of Health. Injury Survey 2008. Hong Kong SAR: Department of Health, 2010.

7. Hawley CA, Ward AB, Long J, et al. Prevalence of traumatic brain injury amongst children admitted to hospital in one health district: a population-based study. Injury 2003;34:256-60.

8. Brookes M, MacMillan R, Cully $\mathrm{S}$, et al. Head injuries in accident and emergency departments. How different are children from adults? J Epidemiol Community Health 1990;44:147-51.

9. Linnan M, UNICEF. Child mortality and injury in Asia: an overview. UNICEF Innocenti Research Centre, 2008.

10. Miller TR, Romano EO, Spicer RS. The cost of childhood unintentional injuries and the value of prevention. Future Child 2000;10:137-63.

11. Peden M. World report on child injury prevention. World Health Organization, 2008.

12. Bulut M, Koksal O, Korkmaz A, et al. Childhood falls: characteristics, outcome, and comparison of the Injury Severity Score and New Injury Severity Score. Emerg Med J 2006;23:540-5.
13. Rivara FP, Alexander B, Johnston B, et al. Population-based study of fall injuries in children and adolescents resulting in hospitalization or death. Pediatrics 1993;92:61-61.

14. Li L, Ozanne-Smith J. Injury hospitalisation rates in Victoria 1987-97: trends, age and gender patterns. Aust N Z J Public Health 2000;24:158-65.

15. Langlois JA, Buechner JS, O'Connor EA, et al. Improving the E coding of hospitalizations for injury: do hospital records contain adequate documentation? Am J Public Health 1995;85: $1261-5$.

16. Watson WL, Mitchell R. Conflicting trends in fall-related injury hospitalisations among older people: variations by injury type. Osteoporos Int 2011;22:2623-31.

17. Alexander BH, Rivara FP, Wolf ME. The cost and frequency of hospitalization for fall-related injuries in older adults. Am J Public Health 1992;82:1020-3.

18. Chien WC, Lai CH, Chung $\mathrm{CH}$, et al. A retrospective population-based data analyses of unintentional fall mortality and hospitalisation in Taiwan during 2005-2007. Int J Inj Contr Saf Promot 2013;20:50-8

19. Statistics NCfH. The International Classification of Diseases: 9th Revision, Clinical Modification: ICD-9-CM. US Department of Health and Human Services, Public Health Service, Health Care Financing Administration, 1989.

20. Wai AK, Chor C, Lee AT, et al. Analysis of trends in emergency department attendances, hospital admissions and medical staffing in a Hong Kong university hospital: 5-year study. Int J Emerg Med 2009;2:141-8.

21. Schull MJ, Stukel TA, Vermeulen MJ, et al. Effect of widespread restrictions on the use of hospital services during an outbreak of severe acute respiratory syndrome. CMAJ 2007;176: 1827-32

22. Chang $\mathrm{HJ}$, Huang $\mathrm{N}$, Lee $\mathrm{CH}$, et al. The impact of the SARS epidemic on the utilization of medical services: SARS and the fear of SARS. Am J Public Health 2004;94:562-4.

23. Liggins $\mathrm{K}$. Inappropriate attendance at accident and emergency departments: a literature review. J Adv Nurs 1993;18: 1141-5.

24. Grumbach K, Keane D, Bindman A. Primary care and public emergency department overcrowding. Am J Public Health 1993;83:372-8.

25. Calnan M. Managing 'minor' disorders: pathways to a hospital accident and emergency department. Sociol Health IIIn 1983;5:149-67.

26. Chung $\mathrm{C}$. Emergency department misuse and administrative interventions. Hong Kong J Emerg Med 2000;7:220-30.

27. Lee A, Lau FL, Hazlett CB, et al. Factors associated with non-urgent utilization of accident and emergency services: a case-control study in Hong Kong. Soc Sci Med 2000;51:1075-85.

28. Samuel N, Jacob R, Eilon $\mathrm{Y}$, et al. Falls in young children with minor head injury: a prospective analysis of injury mechanisms. Brain Inj 2015;29:946-50.

29. Nevitt MC, Cummings SR. Type of fall and risk of hip and wrist fractures: the study of osteoporotic fractures. J Am Geriatr Soc 1993:41:1226-34

30. Rubenstein LZ. Falls in older people: epidemiology, risk factors and strategies for prevention. Age Ageing 2006;35(Suppl 2): ii37-41.

31. Chen HC, Ashton-Miller JA, Alexander NB, et al. Effects of age and available response time on ability to step over an obstacle. $J$ Gerontol 1994:49:M227-M33.

32. Cao C, Ashton-Miller JA, Schultz AB, et al. Abilities to turn suddenly while walking: effects of age, gender, and available response time. J Gerontol A Biol Sci Med Sci. 1997;52:M88-93.

33. Chow CB, Wong WHS, Leung WC, et al. Effectiveness of a technology-based injury prevention program for enhancing mother's knowledge on child safety: a randomized controlled trial protocol. JMIR Research Protocols 2016;5:e205. 